\title{
BMJ Open Risk factors and clinical features of ovarian pregnancy: a case-control study
}

\author{
Qian Zhu, ${ }^{1}$ Cheng Li, ${ }^{1}$ Wei-Hong Zhao, ${ }^{1}$ Jiang-Jing Yuan, ${ }^{1}$ Ming-Xing Yan, ${ }^{1}$ \\ Guo-Juan Qin, ${ }^{2}$ Jian Zhang ${ }^{1}$
}

To cite: Zhu Q, Li C, Zhao W-H, et al. Risk factors and clinical features of ovarian pregnancy: a casecontrol study. BMJ Open 2014:4:e06447.

doi:10.1136/bmjopen-2014006447

- Prepublication history for this paper is available online. To view these files please visit the journal online (http://dx.doi.org/10.1136/ bmjopen-2014-006447).

$Q \mathrm{Z}$ and $\mathrm{C} L$ contributed equally.

Received 24 August 2014 Revised 7 October 2014 Accepted 10 October 2014

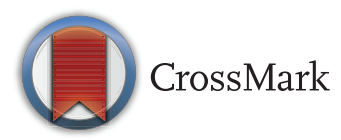

${ }^{1}$ Department of Obstetrics and Gynecology, International Peace Maternity and Child Health Hospital, School of Medicine, Shanghai Jiaotong University, Shanghai, China ${ }^{2}$ Department of Obstetrics and Gynecology, Minhang Central Hospital, Shanghai, China

Correspondence to Professor Jian Zhang; zhangjian_ipmch@sjtu.edu.cn

\section{ABSTRACT}

Objective: To identify risk factors for ovarian pregnancy (OP) and compare clinical features between $\mathrm{OP}$ and tubal pregnancy (TP) patients.

Design: Case-control study.

Setting: University hospital.

Participants: A case-control study was conducted from January 2005 to May 2014. Women diagnosed with OP

were recruited as the case group $(\mathrm{n}=71), 145$ women with TP and 146 with intrauterine pregnancy (IUP) were matched as controls at a ratio of 1:2:2. Women who refused interviews or provided incomplete information were excluded.

Results: OP risk was lower than TP risk in women with serological evidence of Chlamydia trachomatis infection (adjusted $\mathrm{OR}_{1} 0.17,95 \% \mathrm{Cl} 0.06$ to 0.52 ), previous adnexal surgery (adjusted $\mathrm{OR}_{1} 0.25,95 \% \mathrm{Cl} 0.07$ to 0.95 ), and current levonorgestrel emergency contraceptive use (adjusted $\mathrm{OR}_{1} 0.24,95 \% \mathrm{Cl} 0.07$ to 0.78). In vitro fertilisation-embryo transfer (IVF-ET) carried a higher risk of $\mathrm{OP}$ (adjusted $\mathrm{OR}_{1} 12.18,95 \% \mathrm{Cl}$ 2.23 to 66.58 ) than natural conception. When Controlled by IUP women, current users of intrauterine devices (IUDs) carried a higher risk of OP than non-users of any contraceptives (adjusted $\mathrm{OR}_{2} 9.60,95 \% \mathrm{Cl} 1.76$ to 42.20). $\beta$-Human chorionic gonadotropin (hCG) levels on the day of surgery were higher in OP patients than in TP patients $(p<0.01)$. Women with $O P$ were less likely to initially present with vaginal bleeding than those with TP $(p=0.02)$. Moreover, shock $(p=0.02)$, rupture $(p<0.01)$, haemoperitoneum $(p<0.01)$ and emergency laparotomy $(p<0.01)$ were more common in the OP group than in the TP group.

Conclusions: IVF-ET and IUD use may be risk factors for $\mathrm{OP}$, and OP patients tend to have high $\beta$-hCG levels and a poor clinical outcome (shock, rupture, haemoperitoneum and need for emergency laparotomy). Our findings may contribute to the prevention and early diagnosis of $\mathrm{OP}$.

\section{INTRODUCTION}

Primary ovarian pregnancy $(\mathrm{OP})$, where the gestational sac is implanted in the ovary, is one of the rarest forms of ectopic pregnancy. Its incidence after natural conception ranges from $1 / 2000$ to $1 / 60000$ deliveries, accounting for $3 \%$ of all ectopic pregnancies. ${ }^{12}$ Since

\section{Strengths and limitations of this study}

- The present study was the first to explore risk factors for ovarian pregnancy (OP).

- This study initially compared clinical manifestations between OP and tubal pregnancy (TP) patients.

- We chose TP and IUP women as controls to thoroughly explore the risk factors for OP.

- As a hospital based case-control study, selection bias was inevitable.

- There were a limited number of OP patients in this study due to the low incidence of the disease.

the first case was reported in 1682, OP has become an important concern in the field of obstetrics and its incidence is reportedly increasing. ${ }^{34}$

It is difficult to diagnose OP and differentiate it from haemorrhagic ovarian cyst and tubal pregnancy (TP) before operation. Because of the increased vascularity of ovarian tissue, OP usually results in rupture and haemoperitoneum, making it a life-threatening gynaecological emergency. Therefore, counselling of high-risk patients before conception and better understanding of the risk factors can aid in the rapid diagnosis of $O P$ and improve prognosis. However, the risk factors for OP are poorly studied. Seinera $e t a l^{1}$ speculated that the risk factors for OP differed from the traditional risk factors for TP. In contrast, some researchers believe that increased OP risk may be associated with factors such as endometriosis, previous adnexal surgeries, previous infectious diseases, history of infertility, in vitro fertilisation and embryo transfer (IVF-ET), polycystic ovarian syndrome and intrauterine device (IUD) use. ${ }^{2}{ }^{5-7}$ Whether these factors play aetiological roles in the increasing occurrence of OP remains debated, and the exact risk factors for OP remain to be ascertained.

To the best of our knowledge, the present study is the first to examine risk factors associated with OP and to compare clinical manifestations between OP and TP patients. 


\section{METHODS}

\section{Study design and participants}

This study was conducted between January 2005 and May 2014 at the International Peace Maternity and Child Health Hospital in Shanghai, China. It was approved by the institutional review board of the hospital, and written informed consent was obtained from all participating women. The participants were informed that they had the right to refuse to participate in the study or withdraw from the study at any time and were assured that their information would be kept strictly confidential.

Women who were intraoperatively diagnosed with OP on pathological examination according to the Spiegelberg criteria $^{8}$ were recruited in the case group (OP group). Two control groups were formed including a TP group and an intrauterine pregnancy (IUP) group. The TP participants were from the in-patient department of the hospital and had a pathological diagnosis of ectopic pregnancy in the fallopian tube. The IUP participants were recruited from the prenatal clinic and family planning clinic of the same hospital, and IUP was confirmed on the basis of ultrasonography and serum $\beta$-human chorionic gonadotropin ( $\beta$-hCG) levels. All three groups were matched in terms of age ( \pm 5 years) and gestational age ( \pm 7 days), and the number of participants was roughly distributed in a ratio of 1:2:2 in the OP $(n=77)$, TP $(n=155)$ and IUP $(n=156)$ groups.

\section{Data collection and patient examination}

Data on sociodemographic characteristics (including age (four categories: $\leq 24,25-29,30-35$ and $\geq 35$ years), marital status (unmarried or married), education (four categories: primary school or lower, middle school, high school, or collage or above), occupation (three categories: employed, self-employed, or unemployed), personal annual income (three categories: <¥50 000, ¥50 000100000 , or $>¥ 100000$ ), and smoking (non-smoking or smoker)); reproductive, gynaecological and surgical history (including number of previous abortions (four categories: $0,1,2$, or $\geq 3$ ), parity (three categories: 0,1 , or $\geq 2$ ), history of previous ectopic pregnancy (no or yes), serum Chlamydia trachomatis (CT) IgG test (negative or positive), previous infertility (three categories: no, tubal infertility, or other type of infertility), the mode of pregnancy (three categories: natural conception, IVF-ET, or other assisted reproductive technology), a history of caesarean section (no or yes), adnexal surgery (no or yes), and previous appendectomy (no or yes)); and current contraceptive use (six categories: none users, IUD, oral contraceptive pills, female sterilisation, emergency contraceptive pills or other contraceptive methods) were collected via a questionnaire-based interview. For OP and TP patients, the questionnaire also covered some clinical features (findings at the time of presentation at the hospital, eg, abdominal pain, vaginal bleeding and shock).

Five-millilitres of blood samples were collected from each participant after recruitment and tested for serum CT IgG antibody using an ELISA (Beijing Biosynthesis
Biotechnology, China). For OP and TP patients, another $5 \mathrm{mLs}$ of blood samples were collected on the day of surgery to test for the serum $\beta$-hCG levels. Operation methods used, and the amount of haemoperitoneum detected intraoperatively were also recorded. Serum were used for assay following centrifuging the blood samples, and all assays were conducted within $24 \mathrm{~h}$.

\section{Statistical analysis}

The $\chi^{2}$ test was applied to examine the differences among the three groups. Crude ORs with 95\% CIs were calculated for each factor by using univariate logistic regression. Variables found to be associated with $\mathrm{OP}$ in the univariate analysis were included in a multivariate logistic regression analysis by forward selection.

To identify differences in clinical features between the OP and TP groups, Student $t$ test was used for continuous variables, while the $\chi^{2}$ test was used for categorical variables. Data with Poisson distribution (serum $\beta$-hCG level and amount of haemoperitoneum) were later analysed with 10 at the bottom of logarithmic transformation.

Statistical analysis was performed using Statistical Analysis System software (V.8.2; SAS Institute Inc, Cary, North Carolina, USA). $p$ Values were estimated using twotailed tests, and considered statistically significant if less than 0.05 .

\section{RESULTS}

\section{Univariate analysis}

The subject recruitment process is shown in figure 1 . The study finally included 71 women with OP, 145 with TP and 146 with IUP, after 27 participants who refused the interview or provided incomplete information were excluded ( 7 in the OP group, 10 in the TP group and 10 in the IUP group).

The distribution of sociodemographic characteristics among the three groups is listed in table 1 . No differences were observed in age, marital status, educational attainment, personal annual income and smoking. However, a significant difference was found in occupation $(\mathrm{p}=0.02)$.

Table 2 shows the association between OP risk and the participants' reproductive, gynaecological and surgical history, and current contraceptive use. In women who had no abortions previously, the OR of OP among women who had two abortions was lower than in those who had not $\left(\mathrm{OR}_{1} 0.37,95 \%\right.$ CI 0.16 to 0.90$)$. In addition, when using TP women as controls, the ORs of OP were significantly lower in women who had a history of ectopic pregnancy $\left(\mathrm{OR}_{1} 0.24,95 \% \mathrm{CI} 0.07\right.$ to 0.82$)$, a positive reaction to the CT IgG antibody ( $\mathrm{OR}_{1} 0.34,95 \%$ CI 0.16 to 0.72$)$ and a history of previous adnexal surgery $\left(\mathrm{OR}_{1} 0.28,95 \%\right.$ CI 0.11 to 0.71 ). However, when using IUP women as controls, the OR of OP was higher in women with tubal infertility than in those without $\left(\mathrm{OR}_{1} 4.48,95 \%\right.$ CI 1.44 to 13.98). The OR of OP among current IUD users was significantly higher than non-users of any contraceptives $\left(\mathrm{OR}_{2} 8.42\right.$, $95 \%$ CI 1.68 to 42.20$)$. 


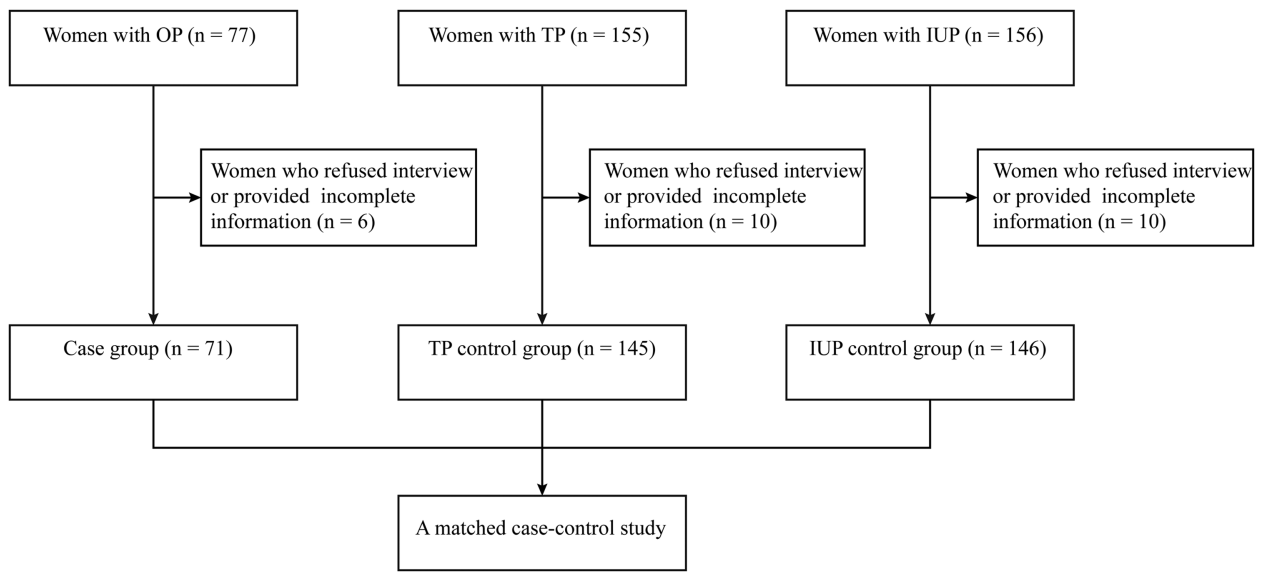

Figure 1 Recruitment profile of this study.

\section{Multivariate analysis}

Variables from the univariate analyses that were included in the multivariate analysis are listed in table 3 . The final model included only a positive result in the serum CT IgG test, mode of pregnancy, previous adnexal surgery and current contraceptive use.

Compared to the risk of TP, that of OP was lower in women with serological evidence of previous CT infection (adjusted $\mathrm{OR}_{1} 0.17,95 \%$ CI 0.06 to 0.52 ), previous adnexal surgery (adjusted $\mathrm{OR}_{1} 0.25,95 \%$ CI 0.07 to 0.95 ) and current use of levonorgestrel emergency contraceptive (LNG-EC; adjusted $\mathrm{OR}_{1} 0.24,95 \%$ CI 0.07 to 0.78 ), and other contraceptive methods (adjusted $\mathrm{OR}_{1}$ 0.34, $95 \%$ CI 0.03 to 0.87 ). In contrast, women who underwent IVF-ET were at a higher risk of OP (adjusted $\mathrm{OR}_{1} 12.18$, $95 \%$ CI 2.23 to 66.58 ) than those who conceived naturally. Further, the incidence of OP was significantly higher than that of IUP among current users of IUDs than among non-users of any contraceptives (adjusted OR: $9.60,95 \%$ CI 1.76 to 42.20 ; data not shown in table).

\begin{tabular}{|c|c|c|c|c|c|c|c|}
\hline & \multicolumn{2}{|l|}{ OP } & \multicolumn{2}{|l|}{ TP } & \multicolumn{2}{|l|}{ IUP } & \multirow[b]{2}{*}{ p Value } \\
\hline & $\mathrm{n}^{*}$ & (\%) & $\mathrm{n}^{\star}$ & (\%) & $\mathbf{n}^{\star}$ & (\%) & \\
\hline \multicolumn{8}{|l|}{ Sociodemographic characteristics } \\
\hline Age (years) & & & & & & & 1.00 \\
\hline$\leq 24$ & 8 & $(11.43)$ & 16 & $(11.03)$ & 17 & $(11.64)$ & \\
\hline $25-29$ & 19 & (27.14) & 40 & (27.59) & 37 & (25.34) & \\
\hline 30-34 & 32 & (45.71) & 66 & (45.52) & 70 & (47.95) & \\
\hline$\geq 35$ & 11 & (15.72) & 23 & (15.86) & 22 & (15.07) & \\
\hline Marital status & & & & & & & 0.75 \\
\hline Married & 66 & (92.96) & 135 & (93.10) & 139 & (95.21) & \\
\hline Unmarried & 4 & $(5.63)$ & 10 & $(6.90)$ & 7 & $(4.80)$ & \\
\hline Education & & & & & & & 0.08 \\
\hline Primary school or lower & 11 & (15.71) & 45 & (31.03) & 25 & (17.12) & \\
\hline Middle school & 5 & $(7.14)$ & 14 & $(9.66)$ & 13 & $(8.90)$ & \\
\hline High school & 9 & (12.00) & 16 & (11.03) & 18 & (12.33) & \\
\hline College or above & 45 & (64.29) & 70 & (48.27) & 90 & (61.64) & \\
\hline Occupation & & & & & & & 0.02 \\
\hline Employed & 61 & (87.14) & 101 & (69.66) & 122 & (83.56) & \\
\hline Self-employed & 2 & $(2.86)$ & 18 & (12.41) & 10 & $(6.85)$ & \\
\hline Unemployed & 7 & (10.00) & 26 & (17.93) & 14 & (9.59) & \\
\hline Personal annual income (RMB) & & & & & & & 0.04 \\
\hline$<50000$ & 23 & $(37.10)$ & 57 & (39.31) & 65 & $(44.52)$ & \\
\hline $50000-100000$ & 26 & (41.94) & 43 & (29.66) & 57 & (39.04) & \\
\hline$>100000$ & 13 & (20.97) & 45 & (31.03) & 24 & (16.44) & \\
\hline Smoking & & & & & & & 0.76 \\
\hline Non-smoking & 68 & (97.14) & 138 & (95.17) & 134 & (95.04) & \\
\hline Smokers & 2 & $(2.86)$ & 7 & $(4.83)$ & 7 & $(4.97)$ & \\
\hline
\end{tabular}

*The sum does not equal the sample size for all variables because of missing data. IUP, intrauterine pregnancy; RMB, ren min bi; OP, ovarian pregnancy; TP, tubal pregnancy. 
Table 2 Reproductive, gynaecological and surgical history of all enrolled participants

\begin{tabular}{|c|c|c|c|c|c|c|c|c|c|}
\hline & \multicolumn{2}{|l|}{ OP } & \multicolumn{2}{|l|}{ TP } & \multicolumn{2}{|l|}{ IUP } & \multirow{2}{*}{$\begin{array}{l}\text { Crude } \mathrm{OR}_{1} \\
(95 \% \text { CI) } \\
\text { OP vs TP }\end{array}$} & \multirow{2}{*}{$\begin{array}{l}\text { Crude OR } \\
(95 \% \text { Cl)† } \\
\text { OP vs IUP }\end{array}$} & \multirow[b]{2}{*}{ p Value } \\
\hline & $\overline{n \ddagger}$ & (\%) & $\overline{\mathbf{n}}$ & (\%) & $\overline{n \ddagger}$ & (\%) & & & \\
\hline \multicolumn{10}{|l|}{ Reproductive history } \\
\hline Number of previous abortions & & & & & & & & & 0.29 \\
\hline 0 & 37 & (52.86) & 52 & (36.88) & 64 & $(43.84)$ & Ref & Ref & \\
\hline 1 & 22 & (31.43) & 47 & (33.33) & 41 & (28.08) & 0.85 (0.43 to 1.67$)$ & 0.89 (0.46 to 1.72$)$ & \\
\hline 2 & 8 & (11.43) & 31 & (21.99) & 26 & (17.81) & $0.37(0.16$ to 0.90$)$ & $0.53(0.22$ to 1.30$)$ & \\
\hline$\geq 3$ & 3 & $(4.29)$ & 11 & $(7.80)$ & 15 & (10.27) & 0.33 (0.09 to 1.23$)$ & 0.35 (0.09 to 1.27$)$ & \\
\hline Parity & & & & & & & & & 0.28 \\
\hline 0 & 43 & (61.43) & 64 & (45.39) & 68 & (46.58) & Ref & Ref & \\
\hline 1 & 26 & (37.14) & 69 & (48.94) & 71 & (48.63) & $0.62(0.34$ to 1.12$)$ & $0.59(0.33$ to 1.07$)$ & \\
\hline$\geq 2$ & 1 & (1.43) & 8 & (5.67) & 7 & $(4.80)$ & $0.20(0.02$ to 1.65$)$ & $0.23(0.03$ to 1.95$)$ & \\
\hline \multicolumn{10}{|l|}{ Gynaecological history } \\
\hline Previous ectopic pregnancy & & & & & & & & & $<0.01$ \\
\hline No & 68 & (95.78) & 122 & (84.72) & 144 & (98.63) & Ref & Ref & \\
\hline Yes & 3 & (4.23) & 22 & (15.28) & 2 & (1.37) & 0.24 (0.07 to 0.82$)$ & 3.22 (0.52 to 19.45$)$ & \\
\hline Serum CT IgG test & & & & & & & & & $<0.01$ \\
\hline Negative & 57 & (85.08) & 95 & (65.97) & 128 & (90.14) & Ref & Ref & \\
\hline Positive & 10 & (14.93) & 49 & (34.03) & 14 & $(9.86)$ & $0.34(0.16$ to 0.72$)$ & 1.60 (0.67 to 3.83$)$ & \\
\hline Previous infertility & & & & & & & & & 0.002 \\
\hline No & 55 & (84.62) & 111 & (76.55) & 137 & (94.48) & Ref & Ref & \\
\hline Others & 1 & $(1.54)$ & 6 & (4.14) & 3 & (2.07) & 0.34 (0.04 to 2.86$)$ & $0.83(0.09$ to 8.16$)$ & \\
\hline Tubal infertility & 9 & (13.85) & 28 & (19.31) & 5 & (3.45) & 0.65 (0.29 to 1.47$)$ & 4.48 (1.44 to 13.98$)$ & \\
\hline Mode of pregnancy & & & & & & & & & 0.67 \\
\hline Natural conception & 61 & (88.41) & 135 & (93.10) & 144 & (98.63) & Ref & Ref & \\
\hline Other ART & 1 & $(1.45)$ & $3 i$ & (2.21) & 2 & $(1.37)$ & $0.74(0.08$ to 7.24$)$ & $1.18(0.11$ to 13.26$)$ & \\
\hline IVF-ET & 7 & (10.15) & 7( & $(4.83)$ & 0 & $(0.00)$ & 2.21 (0.74 to 6.59$)$ & NA & \\
\hline Previous caesarean section§ & & & & & & & & & 0.71 \\
\hline No & 16 & $(59.26)$ & 38 & (50.00) & 41 & (52.56) & Ref & Ref & \\
\hline Yes & 11 & (40.74) & 38( & (50.00) & 37 & (47.44) & $0.69(0.28$ to 1.67$)$ & $0.76(0.31$ to 1.85$)$ & \\
\hline Previous adnexal surgery & & & & & & & & & $<0.01$ \\
\hline No & 64 & (91.43) & 109 & (75.17) & 141 & (96.58) & Ref & Ref & \\
\hline Yes & 6 & (8.57) & 36 & (24.83) & 5 & (3.43) & $0.28(0.11$ to 0.71$)$ & 2.64 (0.78 to 8.98$)$ & \\
\hline Previous appendectomy & & & & & & & & & 0.56 \\
\hline No & 65 & $(94.20)$ & 138 & (97.18) & 140 & (96.55) & Ref & Ref & \\
\hline Yes & 4 & $(5.80)$ & 4( & (2.82) & 5 & (3.45) & $2.12(0.52$ to 8.76$)$ & $1.72(0.45$ to 6.63$)$ & \\
\hline Current contraceptive experience & & & & & & & & & 0.06 \\
\hline None users & 42 & $(60.00)$ & 86 & (59.31) & 101 & (74.27) & Ref & Ref & \\
\hline Intrauterine device & 7 & (10.00) & 7( & $(4.83)$ & 2 & $(1.47)$ & 2.05 (0.67 to 6.22$)$ & 8.42 (1.68 to 42.20$)$ & \\
\hline Oral contraceptive pills & 1 & (1.43) & 1 & $(0.69)$ & 0 & $(0.00)$ & 2.05 (0.13 to 33.55$)$ & NA & \\
\hline Female sterilisation & 0 & $(0.00)$ & 2( & (1.38) & 0 & $(0.00)$ & NA & NA & \\
\hline Emergency contraceptive pills & 4 & (5.71) & 25 & (17.24) & 8 & $(5.88)$ & 0.33 (0.11 to 1.03$)$ & 1.20 (0.34 to 4.21$)$ & \\
\hline Other contraceptive methods & 16 & (22.86) & 24( & (16.55) & 35 & (25.74) & 1.37 (0.66 to 2.84$)$ & $1.10(0.55$ to 2.20$)$ & \\
\hline
\end{tabular}

Comparison of clinical features between the OP and TP groups

Table 4 outlines the clinical features of patients in the OP and TP groups. Complaints of abdominal pain at presentation were similar between the groups $(p=0.12)$. However, women with OP were less likely to initially present with vaginal bleeding than those with TP $(\mathrm{p}=0.02)$. Moreover, shock $(\mathrm{p}=0.02)$, rupture $(\mathrm{p}<0.01)$, haemoperitoneum $(p<0.01)$ and emergency laparotomy $(p<0.01)$ were more frequent in the OP group than in the TP group.

\section{DISCUSSION}

In this study, we explored the risk factors for OP, and found that IVF-ET and IUD use may be closely related to the occurrence of OP. Furthermore, OP patients tend to 
Table 3 Multivariate logistic regression analysis predicting risk factors for $\mathrm{OP}$

\begin{tabular}{|c|c|c|}
\hline & $\begin{array}{l}\text { Adjusted } \mathrm{OR}_{1} \\
(95 \% \mathrm{Cl})^{\star} \\
\text { OP vs TP }\end{array}$ & p Value \\
\hline $\begin{array}{l}\text { Serum Chlamydia } \\
\text { trachomatis IgG test }\end{array}$ & & $<0.01$ \\
\hline Negative & Ref & \\
\hline Positive & $0.17(0.06$ to 0.52$)$ & \\
\hline Mode of pregnancy & & 0.02 \\
\hline Natural conception & Ref & \\
\hline Other ART & NA & \\
\hline IVF-ET & 12.18 (2.23 to 66.58$)$ & \\
\hline Previous adnexal surgery & & 0.04 \\
\hline No & Ref & \\
\hline Yes & $0.25(0.07$ to 0.95$)$ & \\
\hline $\begin{array}{l}\text { Current contraceptive } \\
\text { experience }\end{array}$ & & 0.03 \\
\hline Non-users & Ref & \\
\hline Intrauterine device & $1.42(0.39$ to 5.18$)$ & \\
\hline Oral contraceptive pills & NA & \\
\hline Female sterilisation & NA & \\
\hline LNG-EC & $0.24(0.07$ to 0.78$)$ & \\
\hline $\begin{array}{l}\text { Other contraceptive } \\
\text { methods } \dagger\end{array}$ & $0.34(0.03$ to 0.87$)$ & \\
\hline \multicolumn{3}{|c|}{$\begin{array}{l}{ }^{*} \mathrm{R}_{1} \text { refers to the OR for OP when using TP patients as control. } \\
\text { All ORs were adjusted for the other variables included in table } 3 \text {, } \\
\text { as well as age and occupation. } \\
\text { †Other contraceptive methods included condoms, the rhythm } \\
\text { method and withdrawal. } \\
\text { LNG-EC, levonorgestrel emergency contraceptive; NA, not } \\
\text { applicable; OP, ovarian pregnancy; Ref, reference; TP, tubal } \\
\text { pregnancy. }\end{array}$} \\
\hline
\end{tabular}

have higher $\beta$-hCG levels than women with IUP, and a poorer clinical outcome than TP patients.

$\mathrm{OP}$ is an extremely rare type of ectopic pregnancy, and few studies including a significant number of OP cases have been reported. Two possible mechanisms have been proposed to explain OP. One hypothesis is that fertilisation occurs normally and implantation in the ovary follows reflux of the conceptus from the tube. ${ }^{2}$ The other suggests that various disturbances in ovum release are responsible for ovarian implantation. ${ }^{9}$ However, the definite aetiology remains unclear. The unusual site and rarity of OP lead to a more complex clinical course, beginning with the difficulty in making an early and accurate diagnosis, which results in an unpredictable outcome and a life-threatening situation if the ovary ruptures. ${ }^{5}$ Therefore, the present study on the risk factors of OP may help in successful primary prevention of OP.

We found that IVF-ET treatment was significantly more common in OP patients than in TP patients, suggesting IVF-ET as an OP risk factor. The incidence of OP following IVF-ET has been estimated to be $6 \%$ of all ectopic pregnancies, ${ }^{10}$ which is much higher than the $3 \%$ reported following natural conception. ${ }^{2}$ There could be various explanations for these findings. One is reverse migration of one of the transferred embryos toward the fallopian tube and implantation in the ovary. ${ }^{11}$ Lesny $e t a l^{12}$ showed that a difficult ET stimulates junctional zone contractions and that strong endometrial waves in the fundal area of the uterus could move mock embryos into the fallopian tubes. They also noted that manipulation with tissue forceps in order to

Table 4 Comparison of clinical features between the OP and TP groups

\begin{tabular}{|c|c|c|c|c|c|}
\hline & \multicolumn{2}{|l|}{ OP } & \multicolumn{2}{|l|}{ TP } & \multirow[b]{2}{*}{ p Value } \\
\hline & $\overline{n^{*}}$ & $(\%)$ & $\overline{n^{*}}$ & (\%) & \\
\hline \multicolumn{6}{|c|}{ Abdominal pain at presentation } \\
\hline Yes & 53 & $(74.65)$ & 93 & $(64.14)$ & \multirow[t]{2}{*}{0.12} \\
\hline No & 18 & $(25.35)$ & 52 & (35.86) & \\
\hline \multicolumn{6}{|c|}{ Vaginal bleeding at presentation } \\
\hline Yes & 48 & $(67.61)$ & 119 & (82.07) & \multirow[t]{2}{*}{0.02} \\
\hline No & 23 & (32.39) & 26 & (17.93) & \\
\hline \multicolumn{6}{|l|}{ Rupture } \\
\hline Yes & 40 & $(56.34)$ & 8 & (5.52) & \multirow[t]{2}{*}{$<0.01$} \\
\hline No & 31 & (43.66) & 137 & $(94.48)$ & \\
\hline \multicolumn{6}{|l|}{ Shock } \\
\hline Yes & 11 & $(15.49)$ & 8 & $(5.52)$ & \multirow{2}{*}{0.02} \\
\hline No & 60 & (84.51) & 137 & $(94.48)$ & \\
\hline \multicolumn{6}{|c|}{ Emergency laparotomy } \\
\hline Yes & 14 & $(19.72)$ & 6 & $(4.14)$ & \multirow[t]{2}{*}{$<0.01$} \\
\hline No & 57 & $(80.28)$ & 139 & $(95.86)$ & \\
\hline \multicolumn{6}{|c|}{ Initial $\beta$-hCG level (IU/mL)† } \\
\hline Mean \pm SD & \multicolumn{2}{|c|}{$3.446 \pm 0.679$} & \multicolumn{2}{|c|}{$3.088 \pm 0.632$} & $<0.01$ \\
\hline \multicolumn{6}{|c|}{ Amount of haemoperitoneum $(\mathrm{mL}) \dagger$} \\
\hline Mean \pm SD & \multicolumn{2}{|c|}{$2.402 \pm 0.438$} & \multicolumn{2}{|c|}{$1.875 \pm 0.453$} & $<0.01$ \\
\hline
\end{tabular}


facilitate ET could affect uterine contractility. Oliveira et $a l^{13}$ stated that blastocyst-stage ET may be associated with ectopic implantation of embryos in the ovaries. Further, the high volume and pressure of the culture medium injected into the uterus, the tilt-down position of the patient during ET, or perforation of the uterus during ET could contribute to the development of OP. ${ }^{14}$ Although all these mechanisms explain how OP occurs after IVF-ET, the mechanism underlying the higher OR of OP than TP in women who underwent IVF-ET remains unclear and requires further study.

IUDs were first reported to be associated with OP in 1976. ${ }^{15}$ However, studies have reported a wide variation in the proportion of OP using IUDs, ranging from $7.1 \%$ to $90 \%,{ }^{16-18}$ and this variation may partly be attributed to the differing prevalence of IUD use in the general population. In the present study, $10 \%(7 / 70)$ patients in the OP group and $1.37 \%$ patients $(2 / 146)$ in the IUP group were current users of IUDs, indicating that women using IUDs are more likely to have OP than IUP. This finding might be associated with the fact that IUDs reduce intrauterine implantation but do not have the same protective effect against OP. As Lehfeldt et al reported, IUD reduced intrauterine implantation by $99.5 \%$, and tubal implantation by $95 \%$, but have little protective effect against $\mathrm{OP}^{19}$ Furthermore, another 12-year experience on 19 cases of OP also noted that an IUD was present in 13 of $19(68 \%)$ of the patients. ${ }^{5}$ Some researchers have speculated that the presence of an IUD in situ may increase host susceptibility to infection, thus increasing the incidence of pelvic inflammatory disease (PID) and the associated sequelae. ${ }^{20}$ On the one hand, OP might occur after PID because of the deciliation of the endosalpinx and ovum transport delay caused by PID. ${ }^{21}$ This finding confirms the aetiological role of IUD in OP as well as suggests that tubal factors may be involved in OP. On the other hand, PID can change the ovarian surface and cause defective ovum release, which can lead to intrafollicular fertilisation.

The present study found that a positive reaction to the CT IgG antibody did not show a stronger association with OP than TP. CT is the most common sexually transmitted infection. ${ }^{22}$ It is commonly asymptomatic, thus leaving women susceptible to infection, leading to colonisation including in the fallopian tube and maintaining an ongoing reservoir for infection. ${ }^{23}$ Ault $e t a l^{24}$ showed that a lower genital tract CT infection could spread to the upper reproductive tract and result in salpingitis with a local inflammatory response, which could lead to a predisposition to tubal implantation. Data from a comparative analysis with a large population of infertile women showed that Chlamydia antibody titres can predict tubal damage and are quantitatively related to the severity of damage. ${ }^{25}$ Further, current knowledge suggests that CT infection induces an inflammatory response that eventually leads to tubal epithelial destruction and functional impairment, caused by a high nitric oxide (NO) output mediated by inducible NO synthases. ${ }^{26}$ CT can lead to ectopic pregnancy by causing tubal abnormalities and dysfunction (eg, abnormal cilia activity or tubal contractility), which is the main reason for $\mathrm{TP}^{27}$ whereas the tubal factor does not seem to be a crucial factor for $\mathrm{OP}^{28}$ Therefore, it was not surprising that CT was associated more strongly with TP than with OP. These findings also explained why previous adnexal surgery was not a risk factor for OP but was for TP.

LNG, a synthetic progestogen, is a widely used EC. ${ }^{29}$ Research has suggested that it acts by delaying the luteinising hormone surge and interfering with ovulation, ${ }^{30}$ thereby preventing pregnancy. However, several cases of ectopic pregnancy following LNG-EC failure have been reported. ${ }^{31}$ In the present study, 4 OPs, 25 TPs and 8 IUPs were observed among 37 women with LNG-EC failure. Compared with non-users of contraceptives, women who used LNG-EG did not show an increased risk of OP compared to TP. This finding may be associated with the fact that an elevated progesterone concentration could theoretically impair cilia motility in the fallopian tube and lead to a predisposition to tubal implantation in women using progestin-only pills. ${ }^{33}$ An important part of this study was that clinical features were compared between OP and TP, which, to the best of our knowledge, has not been done previously. We found a significant difference between these groups with respect to vaginal bleeding. OP patients were less likely to present vaginal bleeding than TP patients. This finding may be associated with the fact that because of the increased vascularity of ovarian tissue in OP patients, the endometrium is well maintained with high $\beta$-hCG levels in these patients, unlike in the case of TP patients. Many patients consider bleeding the principal sign of an abnormal pregnancy and it is often their strongest motivation to seek medical attention. Without bleeding, patients may be reassured by amenorrhoea as a sign of a normal IUP, ${ }^{34}$ which might delay the diagnosis and treatment of OP. Therefore, even in patients who do not present with vaginal bleeding, strong suspicion of pregnancy is prudent in order to avoid missing a case of OP.

Our study clearly found higher $\beta$-hCG levels on the day of surgery in OP patients than those in TP patients. This may be attributed to the proper embryonic development resulting from the increased vascularity of ovarian tissue in the former. The incidence of rupture was significantly higher in the OP group $(56.34 \%)$ than the TP group $(5.52 \%)$. Some researchers have speculated that a high $\beta$-hCG level was often related to the rupture in ectopic pregnancy, ${ }^{35}$ thus, from our findings, we hypothesised that high $\beta$-hCG levels are associated with ovary rupture and predict a poor prognosis in OP patients.

Interestingly, this study found a higher incidence of emergency laparotomy and shock in OP patients than in TP patients. Further, the incidence of haemoperitoneum during the operation was significantly higher in the OP group than in the TP group. These findings collectively indicate that OP patients tend to have a poorer prognosis than TP patients.

Although our data is interesting and initially provide information focused on the aetiological research of OP, 
the recognised drawbacks of retrospective, hospital-based case-control studies must be acknowledged, and the quality of the outcome data may also be biased due to recall bias and selection bias. Another important limitation of the study was the limited sample size due to the extremely low incidence of OP. In this study, there were also a small number of OP patients who underwent IVF-ET, thus, despite the fact that IVF-ET appeared to be a high risk for OP, the CI was relative wide. Therefore, sample size should be enlarged and a prospective cohort study should be further designed to validate the results of this study.

\section{CONCLUSION}

Our findings indicated that IVF-ET and current IUD use are risk factors of OP, while previous adnexal surgery, a positive reaction to CT IgG antibody, and LNG-EC use are not associated more strongly with OP than TP. OP patients are more likely to have high $\beta$-hCG levels, accompanied by worse clinical outcomes (shock, rupture, haemoperitoneum and need for emergency laparotomy). These risk factors and clinical features seem to have a high predictive value and may aid in early detection of $\mathrm{OP}$, thereby enabling conservative treatment, reduced mortality and morbidity rates, preservation of fertility and lower overall costs of healthcare for OP.

Contributors JZ conceived, designed and supervised the study as well as critically revised the manuscript. QZ and $C L$ were responsible for drafting and revising the manuscript. W-HZ and G-JQ contributed to statistical analyses and participated in drafting part of the manuscript. M-XY and J-JY contributed to raw data collection. All authors substantially contributed to the revision of the manuscript.

Funding This work was supported by Shanghai Scientific and Technical Committee Grants (124119a4802).

Competing interests None.

Patient consent Obtained.

Ethics approval Ethics approval was obtained from the Ethics Committee of the International Peace Maternity and Child Health Hospital.

Provenance and peer review Not commissioned; externally peer reviewed.

Data sharing statement Extra data can be accessed via the Dryad data repository at http://datadryad.org/ with the doi:10.5061/dryad.tn90g.

Open Access This is an Open Access article distributed in accordance with the Creative Commons Attribution Non Commercial (CC BY-NC 4.0) license, which permits others to distribute, remix, adapt, build upon this work noncommercially, and license their derivative works on different terms, provided the original work is properly cited and the use is non-commercial. See: http:// creativecommons.org/licenses/by-nc/4.0/

\section{REFERENCES}

1. Seinera P, Di Gregorio A, Arisio R, et al. Ovarian pregnancy and operative laparoscopy: report of eight cases. Hum Reprod 1997:12:608-10.

2. Grimes HG, Nosal RA, Gallagher JC. Ovarian pregnancy: a series of 24 cases. Obstet Gynecol 1983;61:174-80.

3. Lurie S. The history of the diagnosis and treatment of ectopic pregnancy: a medical adventure. Eur J Obstet Gynecol Reprod Biol 1992;43:1-7.

4. Abidi A, Gordon R, Harman MB, et al. Ovarian pregnancy without definitive pathologic confirmation: a case report. J Reprod Med 2007;52:320-2.
5. Raziel A, Schachter M, Mordechai E, et al. Ovarian pregnancy-a 12-year experience of 19 cases in one institution. Eur J Obstet Gynecol Reprod Biol 2004;114:92-6.

6. Shiau CS, Hsieh CL, Chang MY. Primary ovarian pregnancy. Int $J$ Gynaecol Obstet 2007;96:127.

7. Tinelli A, Hudelist G, Malvasi A, et al. Laparoscopic management of ovarian pregnancy. JSLS 2008;12:169-72.

8. O S: Casuistry in ovarian pregnancy. ArchGynaekol 1878:73-9.

9. Hallatt JG. Primary ovarian pregnancy: a report of twenty-five cases. Am J Obstet Gynecol 1982;143:55-60.

10. Marcus SF, Brinsden PR. Analysis of the incidence and risk factors associated with ectopic pregnancy following in-vitro fertilization and embryo transfer. Hum Reprod 1995;10:199-203.

11. Knutzen V, Stratton CJ, Sher G, et al. Mock embryo transfer in early luteal phase, the cycle before in vitro fertilization and embryo transfer: a descriptive study. Fertil Steril 1992;57:156-62.

12. Lesny P, Killick SR, Robinson J, et al. Junctional zone contractions and embryo transfer: is it safe to use a tenaculum? Hum Reprod 1999;14:2367-70.

13. Oliveira FG, Abdelmassih V, Costa AL, et al. Rare association of ovarian implantation site for patients with heterotopic and with primary ectopic pregnancies after ICSI and blastocyst transfer. Hum Reprod 2001;16:2227-9.

14. Atabekoglu CS, Berker B, Dunder I. Ovarian ectopic pregnancy after intracytoplasmic sperm injection. Eur J Obstet Gynecol Reprod Biol 2004:112:104-6.

15. Rimdusit $P$, Kasatri N. Primary ovarian pregnancy and the intrauterine contraceptive device. Obstet Gynecol 1976;48:57S-9S.

16. Koo YJ, Choi HJ, Im KS, et al. Pregnancy outcomes after surgical treatment of ovarian pregnancy. Int J Gynaecol Obstet 2011;114:97-100.

17. Ko PC, Lo LM, Hsieh TT, et al. Twenty-one years of experience with ovarian ectopic pregnancy at one institution in Taiwan. Int $J$ Gynaecol Obstet 2012;119:154-8.

18. Raziel A, Golan A, Pansky M, et al. Ovarian pregnancy: a report of twenty cases in one institution. Am J Obstet Gynecol 1990;163:1182-5.

19. Lehfeldt $\mathrm{H}$, Tietze $\mathrm{C}$, Gorstein F. Ovarian pregnancy and the intrauterine device. Am J Obstet Gynecol 1970;108:1005-9.

20. Eschenbach DA. Earth, motherhood, and the intrauterine device. Fertil Steril 1992; 57:1177-9.

21. Herbertsson G, Magnusson SS, Benediktsdottir K. Ovarian pregnancy and IUCD use in a defined complete population. Acta Obstet Gynecol Scand 1987:66:607-10.

22. Bebear C, de Barbeyrac B. Genital Chlamydia trachomatis infections. Clin Microbiol Infect 2009;15:4-10.

23. Pientong C, Ekalaksananan T, Wonglikitpanya N, et al. Chlamydia trachomatis infections and the risk of ectopic pregnancy in Khon Kaen women. J Obstet Gynaecol Res 2009;35:775-81.

24. Ault KA, Statland BD, King MM, et al. Antibodies to the chlamydial 60 kilodalton heat shock protein in women with tubal factor infertility. Infect Dis Obstet Gynecol 1998:6:163-7.

25. Akande VA, Hunt LP, Cahill DJ, et al. Tubal damage in infertile women: prediction using chlamydia serology. Hum Reprod 2003;18:1841-7.

26. Shao R, Zhang SX, Weijdegard B, et al. Nitric oxide synthases and tubal ectopic pregnancies induced by Chlamydia infection: basic and clinical insights. Mol Hum Reprod 2010;16:907-15.

27. Shaw JL, Dey SK, Critchley HO, et al. Current knowledge of the aetiology of human tubal ectopic pregnancy. Hum Reprod Update 2010:16:432-44.

28. Dursun P, Gultekin M, Zeyneloglu HB. Ovarian ectopic pregnancy after ICSI-ET: a case report and literature review. Arch Gynecol Obstet 2008;278:191-3.

29. Gemzell-Danielsson K. Mechanism of action of emergency contraception. Contraception 2010;82:404-9.

30. Croxatto HB, Brache V, Pavez M, et al. Pituitary-ovarian function following the standard levonorgestrel emergency contraceptive dose or a single $0.75-\mathrm{mg}$ dose given on the days preceding ovulation. Contraception 2004:70:442-50.

31. Kozinszky Z, Bakken RT, Lieng M. Ectopic pregnancy after levonorgestrel emergency contraception. Contraception 2011;83:281-3.

32. Matsushita $\mathrm{H}$, Takayanagi $\mathrm{T}$, Ikarashi $\mathrm{H}$. Ectopic pregnancy following emergency contraception with ethinyloestradiol-levonorgestrel: a case report. Eur J Contracept Reprod Health Care 2007;12:184-6.

33. Paltieli Y, Eibschitz I, Ziskind G, et al. High progesterone levels and ciliary dysfunction-a possible cause of ectopic pregnancy. J Assist Reprod Genet 2000;17:103-6.

34. Butts S, Sammel M, Hummel A, et al. Risk factors and clinical features of recurrent ectopic pregnancy: a case control study. Fertil Steril 2003;80:1340-4.

35. Goksedef BP, Kef S, Akca A, et al. Risk factors for rupture in tubal ectopic pregnancy: definition of the clinical findings. Eur J Obstet Gynecol Reprod Biol 2011;154:96-9. 